\title{
Lakon Baratayuda Versi Klaten: Kajian Struktur Naratif
}

\author{
Endah Budiarti ${ }^{1}$ \\ Jurusan Seni Pedalangan, Fakultas Seni Pertunjukan, Institut Seni Indonesia Yogyakarta
}

\begin{abstract}
Tulisan ini dimaksudkan untuk menemukan aliran tindakan hero dalam Lakon Baratayuda versi Klaten. Teori struktur cerita rakyat Vladimir Propp diadaptasi dan dimodifikasi dalam tulisan ini. Teori Propp mengatakan bahwa sebuah cerita rakyat memiliki struktur yang dibentuk dari fungsi-fungsi yang bergerak berurutan. Berdasarkan teori tersebut, metode analisis yang digunakan dalam tulisan ini adalah metode struktural model Propp. Upaya untuk dapat menemukan aliran tindakan sang hero pertama-tama dilacak apa saja fungsi (tindakan pelaku) yang hadir dalam LBY versi Klaten, kemudian dilacak urutan fungsi pelaku (tindakan pelaku) dalam LBY versi Klaten dan yang terakhir dilacak struktur naratif LBY versi Klaten. Ada beberapa hal yang dapat dikemukakan dari analisis terhadap LBY versi Klaten. Pertama, ditemukan empat belas fungsi (tindakam hero) yang dilacak dari aliran tindakan hero dalam LBY versi Klaten. Kedua, LBY versi Klaten memuat lebih dari satu pergerakan cerita.
\end{abstract}

Kata kunci: Barata yuda, Klaten, Vladimir Propp

\section{ABSTRACT}

Lakon Baratayuda versi Klaten: Study of Narative Structure. This paper is intended to find the flow of the action hero in the Lakon Baratayuda Klaten version. The theory of the structure of folk tales Vladimir Propp adapted and modified in this paper. Propp's theory says that a folk tale has a structure formed of functions that move sequentially. With regard to the theory, the method of analysis used is the method of Propp's structural models. To be able to find the flow of the action hero first revealed what functions (action dramatic personae) are present, then determine the sequence of functions (action dramatic personae), and further reveals the narrative structure of the Lakon Baratayuda Klaten version. There are several things that can be raised from the analysis of Lakon Baratayuda Klaten version. The first, discovered fourteen function (action hero) is tracked from the stream acts as a hero in the Lakon Baratayuda Klaten version. Second, the Lakon Baratayuda Klaten version contains more than one main story movement.

Keywords: Baratayuda, structural, Propp

\section{Pendahuluan}

Lakon Baratayuda menceritakan perang besar yang terjadi antara dua saudara keturunan Barata yaitu Korawa dan Pandawa (Heroesoekarto, 1961:5). Lakon Baratayuda (selanjutnya dalam tulisan ini disebut $L B Y$ ) merupakan salah satu dari ratusan episode lakon wayang kulit purwa yang memiliki keistimewaan dibanding lakon-lakon yang lain. Dikatakan istimewa karena bagi sebagian masyarakat Jawa, $L B Y$ dianggap sebagai lakon keramat dan tidak boleh dipertunjukkan di sembarang tempat dan waktu. Menurut kepercayaan yang masih berlaku, apabila larangan dilanggar akan menimbulkan bencana. Kepercayaan ini menyebabkan $L B Y$ hanya dipertunjukkan pada saat-saat tertentu yaitu saat upacara bersih desa yang hanya berlangsung setahun sekali. Pada beberapa dusun di kabupaten Klaten Jawa Tengah, LBY merupakan lakon pokok untuk keperluan upacara tahunan rasulan, sadranan, dan bersih desa sebagai simbol penolak marabahaya (Marsono, 1993:47-48).

Keistimewaan $L B Y$ yang lain, khususnya $L B Y$ versi Klaten yang dalam tulisan ini dipakai sebagai data yang dianalisis, ialah lakon ini mempunyai jalinan cerita yang khas bila dibandingkan dengan $L B Y$ pada beberapa sumber cerita lakon wayang kulit purwa. $L B Y$ versi Klaten menceritakan peperangan antara Korawa dan Pandawa dalam satu lakon, sedangkan dalam beberapa sumber cerita wayang $L B Y$ dibagi menjadi beberapa lakon. Disebutkan di sini beberapa sumber cerita lakon wayang kulit purwa yang dapat dilacak misalnya, Serat Pedhalangan Ringgit Purwa (Subalidinata, 1989:26) cerita perang Baratayuda dibagi menjadi sebelas episode yaitu Lakon Kresna Duta, Lakon Jabelan, Lakon Kresna Gugah, Lakon Bisma Gugur, Lakon Angkawijaya Gugur, Lakon Jayadrata Gugur, Lakon Pejahipun Gathotkaca, Lakon Pejahipun

1 Alamat Korespondensi: Jurusan Seni Pedalangan ISI Yogyakarta. Jalan Parangtritis Km. 6,5 Sewon Yogyakarta. Telepon 0274375380, e-mail: endahbudiarti30@yahoo.co.id. HP: 08562876036. 
Adipati Karna, Lakon Pejahipun Suyudana, dan Lakon Parikesit Lair. Serat Baratayuda ditulis oleh Radyomardowo (1959) yang merupakan transkripsian dari pentas wayang di Sasana Hinggil Dwi Abad pada tahun 1958 dengan mencatat cerita perang Baratayuda yang dibagi menjadi sebelas episode.

$L B Y$ versi Klaten, sebagai sebuah lakon yang sangat panjang, yaitu memuat banyak cerita dan banyak peristiwa yang dalam versi lain dibagi-bagi menjadi beberapa lakon, diasumsikan memiliki struktur naratif atau struktur pergerakan cerita yang khas. Bagaimana struktur naratif $L B Y$ versi Klaten sebagai sebuah cerita rakyat Jawa yang khas merupakan topik yang akan dibahas dalam tulisan ini.

$L B Y$ sebagai salah satu bagian dari beratus-ratus episode lakon wayang kulit purwa, sudah sejak lama mendapat perhatian para peneliti. Berikut akan dikemukakan beberapa tulisan mengenai $L B Y$. J. Kats (1929) dalam bukunya Het Javaansche Toneel: Wajang Poerwa I khusus yang berkaitan dengan $L B Y$ mengemukakan tentang pada awalnya $L B Y$ dipentaskan pada upacara bersih desa di beberapa dukuh di daerah kabupaten Klaten. Tulisan Kats ini memberi informasi bahwa $L B Y$ versi Klaten telah menjadi bagian siklus kehidupan masyarakan Klaten sejak awal abad ke-20 (Kats, 1929). Tulisan lain tentang $L B Y$ adalah penelitian Marsono dan Hanggar (1993) yang berjudul Makna Lakon Baku pada Upacara Tradisional Tahunan di Lingkungan Masyarakat Jawa Tengah, mengemukakan bahwa LBY merupakan lakon baku untuk upacara tahunan di beberapa dusun di kabupaten Klaten.

Melalui dua tulisan ini kiranya dapat dikatakan bahwa $L B Y$ selalu dilihat sebagai lakon yang dipentaskan dalam hubungannya dengan upacara ritual, $L B Y$ sebagai bagian dari cerita rakyat Jawa rupa-rupanya luput dari perhatian. Hal inilah yang ditelisik dalam tulisan ini dengan tujuan agar pemahaman terhadap lakon wayang menjadi lebih komprehensif.

\section{Struktur Naratif Model Vladimir Propp}

Kaca mata Vladimir Propp dalam mengkaji sebuah cerita rakyat digunakan dalam tulisan ini, untuk dapat melihat lakon wayang sebagai bagian cerita rakyat Jawa. Teori struktur naratif cerita rakyat Vladimir Propp dipakai sebagai penuntun analisis dalam tulisan ini, artinya teori Vladimir Propp ini akan diadaptasi dan dimodifikasi untuk menemukan struktur naratif $L B Y$ versi Klaten.

Vladimir Propp berteori bahwa sebuah cerita rakyat memiliki struktur yang dibentuk dari fungsi-fungsi yang bergerak berurutan. Pada umumnya sebuah cerita berawal dari kejahatan atau kekurangan, melalui fungsi-fungsi perantara berakhir dengan perkawinan atau fungsi-fungsi lain yang bertugas sebagai penyelesaian. Fungsifungsi yang bertugas sebagai penyelesaian kadang-kadang berupa penerimaan alat magis, penghapusan penderitaan atau kekurangan, hero (hero) diselamatkan dan sebagainya (Propp, 1988: 92). Adapun yang dimaksud fungsi oleh Vladimir Propp ialah suatu tindakan (action) dari dramatis personae (peran, tokoh, pelaku), didefinisikan dari sudut pandang kepentingannya di dalam aliran tindakan. Fungsi ditetapkan dengan melihat peristiwa di dalam cerita (Propp, 1988:20-21). Hasil penelitiannya terhadap 100 cerita rakyat Rusia, Vladimir Propp mengungkapkan tiga puluh satu fungsi pelaku dengan keteraturan arah naratifnya. Tiap-tiap fungsi pelaku diberi nomor fungsi, ikhtisar singkat tentang hakikat fungsi, definisi yang disingkat dalam satu kata, lambang konvensionalnya, dan beberapa contoh variasi tindakan, untuk mempermudah pembuatan kerangka dan skema pergerakan cerita. Adapun urutan ketiga puluh satu fungsi dari cerita rakyat Rusia yang diteliti oleh Propp (1988: 26-64) adalah sebagai berikut:

1. Seorang anggota keluarga meninggalkan rumah (definisi: ketidakhadiran; lambang $\beta$ )

2. Sebuah larangan ditujukan kepada hero (definisi: larangan, lambang $\gamma$ )

3. Larangan dilanggar (definisi: pelanggaran, lambang $\delta$ )

4. Penjahat menyelidiki bagaimana cara menghalangi atau mencelakai hero (definisi: pengintaian, lambang: $\varepsilon$ )

5. Penjahat menerima informasi tentang korbannya (definisi: penyampaian informasi, lambang: ל)

6. Penjahat memperdaya korbannya dengan tujuan memilikinya atau mendapatkan yang dimiliki korbannya (definisi: penipuan, lambang: $\eta$ )

7. Korban terperdaya oleh tipuan dan tanpa sadar membantu musuhnya (definisi: keterlibatan, lambang: $\theta$ ) 
8. Penjahat merusak atau melukai salah seorang anggota keluarga (definisi: kejahatan, lambang: A)

(8a) Seorang anggota keluarga kekurangan sesuatu atau ingin memiliki sesuatu (definisi: kekurangan, lambang: a)

9. Ketidakberuntungan atau kekurangan membuat hero dikenal, hero diminta atau diperintah, diizinkan untuk pergi atau menjadi penghubung tindakan balasan (definisi: mediasi, peristiwa penghubung, lambang: B)

10. (10) Hero bersepakat untuk melakukan tindak balas (definisi: permulaan tindak balas, lambang: C)

11. Hero meninggalkan rumah (definisi: keberangkatan, lambang: $\uparrow$ )

12. Hero diuji, ditanya, diserang dan lain-lain yang menyebabkannya menerima sesuatu alat magis atau penolong (definisi: fungsi pertama donor, lambang: D)

13. Hero mereaksi tindakan calon donor (definisi: reaksi hero, lambang: E)

14. Hero memperoleh cara penggunaan alat magis (definisi: penerimaan alat magis, lambang: F)

15. Hero dipindahkan, dikirim, atau dipandu ke tempat-tempat keberadaan objek yang dicari (definisi: perpindahan di antara dua ruang, panduan, lambang: $G$ )

16. Hero dan penjahat terlibat peperangan (definisi: perjuangan, lambang: $\mathrm{H}$ )

17. Hero ditandai (definisi: penandaan, lambang: $\mathrm{J})$

18. Penjahat dikalahkan atau dibinasakan (definisi; kemenangan, lambang: I)

19. Kekurangan awal diatasi (lambang K). Fungsi ini dan fungsi kejahatan membentuk satu pasangan. Naratif sampai pada puncaknya pada fungsi ini.

20. Hero kembali/pulang (definisi: kepulangan, lambang: $\downarrow)$

21. Hero dikejar (definisi: pengejaran, lambang: $\operatorname{Pr})$

22. Hero diselamatkan (definisi: penyelamatan, lambang: Rs)

23. Hero yang tidak dikenali tiba di negerinya atau di negeri lain (definisi: kedatangan tidak dikenali, lambang: $\mathrm{O}$ )

24. Hero palsu mempersembahkan tuntutan palsu (definisi: tuntutan palsu, lambang: L)

25. Tugas berat direncanakan untuk hero (definisi: tugas berat, lambang: $\mathrm{M}$ )

26. Tugas diselesaikan (definisi: penyelesaian, lambang: N)

27. Hero dikenali (definisi: pengenalan, lambang: Q)
28. Hero palsu atau penjahat terbongkar (definisi: pembongkaran, lambang: Ex)

29. Hero diberi wujud baru (perubahan wujud, lambang: $\mathrm{T}$ )

30. Panjahat palsu dihukum (definisi: hukuman, lambang U)

31. Hero menikah dan naik tahta (definisi: perkawinan, lambang: W)

Berdasarkan urutan fungsi beserta lambangnya seperti dikemukakan Propp tadi maka sebuah cerita biasanya memiliki skema urutan fungsi sebagai berikut:

$\beta \gamma \delta \varepsilon \zeta \eta \theta \mathrm{A}$ (a) B C $\uparrow \mathrm{DEFGHJIK} \downarrow \operatorname{Pr}$ Rs O L M N Q Ex T UW

Dari paparan di muka, secara singkat skema teori struktur cerita rakyat Vladimir Propp dapat dilihat pada gambar 1. Berdasarkan teori struktural model Propp tersebut maka langkah awal untuk dapat melacak struktur naratif $L B Y$ versi Klaten ialah melacak peristiwa-peristiwa yang terjadi pada setiap adegan. Dari peristiwa-peristiwa tersebut ditemukan siapa pelaku (dramatis personae) dalam peristiwa tersebut dan bagaimana tindakan pelaku dalam menggerakkan cerita. Melalui pelacakan peristiwa ini terungkap apa saja fungsi (tindakan pelaku) yang hadir dalam $L B Y$ versi Klaten, dan juga terungkap urutan fungsi pelaku (tindakan pelaku) dalam $L B Y$ versi Klaten. Terungkapnya fungsi dan urutan fungsi dalam $L B Y$ versi Klaten, maka terungkap pula skema pergerakan cerita $L B Y$ versi Klaten.

\section{Peristiwa-Peristiwa Dalam $L B Y$ versi Klaten}

Peristiwa dalam hal ini dapat dikatakan sebagai kejadian-kejadian penting yang menjalin cerita (Sudjiman, 1990: 62). Pelacakan peristiwa dijadikan sebagai jembatan untuk menentukan fungsi dan urutan fungsi. Berikut adalah peristiwaperistiwa yang berhasil dilacak dalam $L B Y$ versi Klaten. Peristiwa-peristiwa ini dilacak berdasarkan struktur pertunjukan wayang kulit gaya Surakarta seperti diteorikan oleh Nojowirongko (1960) dan Suyanto (2007).

\section{Peristiwa-peristiwa dalam Pathet Nem}

Peristiwa yang mengawali Jejer Pesanggrahan Ngastina ialah peristiwa pertama, memuat cerita kesedihan dan rasa pesimis Duryudana untuk 


\section{pFRUKTUR CERITA RAKYAT}

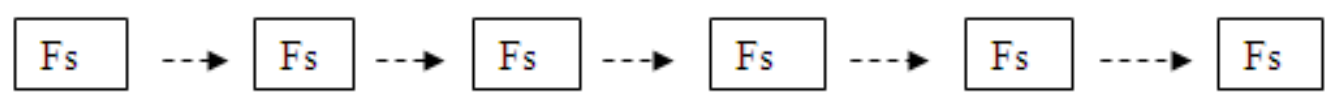

Gambar. 1 Skema struktur naratif Vladimir Propp

Keterangan: $\quad$ Fs: fungsi (tindakan pelaku)

-->: pergerakan linear/pergerakan parallel

melanjutkan perang Baratayuda. Apa yang dirasakan Duryudana itu dilatarbelakangi oleh gugurnya para senapati andalan Korawa. Peristiwa kedua, Patih Sengkuni membangkitkan semangat Duryudana dengan memberi saran untuk segera menyerang Pandawa karena saat itulah saat yang tepat disebabkan Werkudara sedang meninggalkan medan perang akibat kesedihannya atas kematian putranya, Gathutkaca. Peristiwa ketiga, Duryudana, atas pertimbangan Pendhita Dorna, mengangkat Bomawikatha dan Wikathaboma sebagai senapati agung Korawa. Peristiwa keempat, setelah diangkat sebagai senapati, Bomawikatha dan Wikathaboma siap-siap berangkat ke medan Kurusetra.

Peristiwa yang terjadi dalam Adegan Kedhatonan adalah peristiwa kelima, Duryudana mengajak Salya dan Adipati Karna untuk pesta jamuan makan. Pendhita Dorna diminta berdoa bersama-sama demi kemenangan perang.

Peristiwa dalam Adegan Pasowanan nJawi ini merupakan peristiwa keenam, Bomawikatha dan Wikathaboma yang diiringkan barisan prajuritnya berangkat ke medan Kurusetra.

Peristiwa dalam Adegan Pungkuran adalah peristiwa ketujuh, Werkudara sangat sedih dan menyesali kematian putranya, Gathutkaca. Peristiwa kedelapan, Petruk mengingatkan tentang ketidakpantasan sikap Werkudara meninggalkan medan perang. Petruk memberi saran kepada Werkudara untuk menuntut balas kematian Gathutkaca. Peristiwa kesembilan, Werkudara tergugah semangatnya lalu bersumpah tidak akan berkumpul dengan saudara-saudaranya apabila belum berhasil membuat medan Kurusetra banjir darah dan mayat.

Peristiwa kesepuluh merupakan peristiwa dalam Adegan Babak Unjal, Kembar (Nakula dan
Sadewa) diminta untuk memberitahu Werkudara bahwa Werkudara diminta untuk menghadapi senapati Ngastina. Werkudara bersedia. Peristiwa kesebelas, Werkudara meminta agar Kembar menyampaikan permohonan doa restu Werkudara kepada Puntadewa dan Abiyasa. Peristiwa kedua belas, Werkudara berangkat ke medan Kurusetra diiringkan Punakawan.

Peristiwa-peristiwa berikutnya terdapat dalam Adegan Perang di Kurusetra. Peristiwa ketiga belas, Perang antara Werkudara dengan Bomawikatha dan Wikathaboma. Peristiwa keempat belas, Werkudara berhasil membunuh Bomawikatha dan Wikathaboma.

\section{Peristiwa-peristiwa dalam Pathet Sanga}

Peristiwa dalam pathet sanga merupakan kelanjutan dari peristiwa-peristiwa yang terjadi dalam pathet nem. Peristiwa kelima belas merupakan peristiwa dalam Adegan Petamanan, atas perintah Duryudana, Banowati menahan Dursasana agar tetap berada di taman dengan tujuan agar terhindar dari kematian di Kurusetra karena dialah yang kelak dicalonkan menggantikan Duryudana jika gugur di medan laga. Peristiwa keenam belas, Dursasana dengan dalih mencari angin segar, pergi meninggalkan taman menuju ke medan tempur. Peristiwa ketujuh belas, Dursasana berangkat ke medan Kurusetra hendak menantang perang Werkudara.

Peristiwa kedelapan belas merupakan peristiwa yang terjadi dalam Adegan di Kurusetra, peperangan antara Werkudara dan Dursasana. Peristiwa kesembilan belas, Dursasana berhasil dibinasakan oleh Werkudara. Peristiwa kedua puluh termasuk dalam Adegan Pesanggrahan Ngastina, Duryudana sedih atas kematian Dursasana. Peristiwa kedua puluh satu, Adipati Karna menawarkan diri 
sebagai senapati. Peristiwa kedua puluh dua, atas pertimbangan Pendhita Dorna, Adipati Karna diangkat sebagai senapati. Peristiwa kedua puluh tiga, Adipati Karna berangkat ke medan Kurusetra.

\section{Peristiwa-peristiwa dalam Pathet Manyura}

Peristiwa-peristiwa dalam pathet manyura merupakan kelanjutan dari peristiwa-peristiwa dalam pathet sanga. Peristiwa dalam Adegan Pesanggrahan Gupalawiya ialah peristiwa kedua puluh empat, Kresna memberi nasihat kepada Pandawa supaya mereka menghindari tindakan jahat, perkataan yang tidak pantas, tidak melupakan ajaran-ajaran tentang budi baik dan luhur. Jika mereka melupakan nasihat itu maka kekalahan yang akan diterimanya. Peristiwa kedua puluh lima, Setyaki memberitahu bahwa Korawa telah mengangkat Adipati Karna sebagai senapati. Peristwa kedua puluh enam, Krisna meminta Janaka untuk menghadapi Adipati Karna. Peristiwa kedua puluh tujuh, Janaka berangkat ke medan Kurusetra dengan mengendarai kereta.

Adegan di Kurusetra dibuka dengan peristiwa kedua puluh delapan, Hardawalika hendak menuntut balas atas kematian orang tuanya oleh Janaka. Peristiwa kedua puluh sembilan, Hardawalika menawarkan bantuan kepada Adipati Karna dalam pertempuran dengan Janaka. Adipati Karna menolak. Hardawalika diijinkan Adipati Karna untuk membunuh Janaka. Peristiwa ketiga puluh, perang antara Hardawalika dan Janaka. Peristiwa ketiga puluh satu, Hardawalika berhasil dibinasakan oleh Janaka.

Peristiwa ketiga puluh dua mengawali Adegan Karna Tanding. Karna dan Janaka telah berhadapan di medan Kurusetra. Terjadi peperangan hebat. Peristiwa ketiga puluh tiga, Karna berhasil dibunuh atas bantuan (kecurangan) Salya, sais kereta perang Karna.

Peristiwa ketiga puluh empat termasuk dalam Adegan Pesanggrahan Ngastina. Salya mengabarkan kematian Adipati Karna kepada Duryudana. Peristiwa ketiga puluh lima, Aswatama datang kepada Duryudana melaporkan bahwa kematian Adipati Karna disebabkan oleh kecurangan Salya ketika menjadi sais kereta perangnya. Peristiwa ketiga puluh enam, Durna menawarkan diri sebagai senapati Korawa setelah kematian Karna. Penawaran diri Durna dilatarbelakangi oleh kelancangan Aswatama yang telah membuat Salya marah karena dituduh ikut membantu Janaka dalam menghabisi Karna. Peristiwa ketiga puluh tujuh, Durna berangkat ke medan Kurusetra.

Peristiwa yang termasuk dalam Adegan di Kurusetra berikutnya ialah peristiwa ketiga puluh delapan, Durna berhadapan dengan Setyaki di medan Kurusetra. Terjadi peperangan di antara mereka. Setyaki dipukul mundur. Janaka dan Werkudara hendak memberi bantuan dengan membunuh Durna, tetapi mereka mengurungkan niatnya karena rasa hormatnya kepada gurunya. Peristiwa ketiga puluh sembilan, Kresna memberi bantuan berupa siasat bagaimana dapat mengalahkan Durna. Werkudara diminta membunuh gajah Tama. Hal ini dimaksudkan untuk mengacaukan konsentrasi Durna karena mengira anaknya, Aswatama mati. Peristiwa keempat puluh, Trusthajumena yang telah dirasuki arwah Palgunadi membunuh Durna.

Adegan berikutnya adalah Adegan Perang Aswatama melawan Janaka. Peristiwa yang termasuk dalam adegan ini ialah peristiwa keempat puluh satu, Aswatama menuntut balas atas kematian ayahnya, Durna. Peristiwa keempat puluh dua, terjadi peperangan antara Aswatama dengan Janaka. Peristiwa keempat puluh tiga, Narada meminta senjata Cundhamanik milik Aswatama lalu pulang ke Kahyangan.

Peristiwa keempat puluh empat termasuk dalam Adegan Pesanggrahan Ngastina. Patih Sengkuni mengabarkan kematian Durna kepada Duryudana. Peristiwa keempat puluh lima, Salya menawarkan diri menjadi senapati Korawa. Peristiwa keempat puluh enam, Duryudana menyetujui penawaran diri Salya, lalu mengangkat Salya sebagai senapati Korawa. Peristiwa keempat puluh tujuh, Salya berangkat ke medan Kurusetra.

Adegan berikutnya adalah Adegan di Kurusetra. Peristiwa yang termasuk dalam adegan ini ialah peristiwa keempat puluh delapan yaitu peperangan antara Salya melawan Werkudara dan Janaka. Salya berhasil memukul mundur musuhnya. Peristiwa keempat puluh sembilan, Kresna meminta Nakula dan Sadewa berpakaian putih menuju medan Kurusetra. Hal ini merupakan siasat Kresna untuk melemahkan Salya. Nakula dan Sadewa diberitahu kelemahan Salya yaitu dia hanya dapat dikalahkan oleh orang yang berdarah putih. Peristiwa kelima puluh, peperangan antara 
Salya dengan Puntadewa yang notabene adalah orang yang berdarah putih. Peristiwa kelima puluh satu, Salya berhasil dibinasakan oleh Puntadewa.

Adegan selanjutnya adalah Adegan Pesanggrahan Ngastina. Peristiwa kelima puluh dua termasuk dalam adegan ini. Patih Sengkuni mengabarkan kematian Salya kepada Duryudana. Peristiwa kelima puluh tiga, Duryudana berangkat ke medan Kurusetra sebagai senapati.

Peristiwa kelima puluh empat termasuk peristiwa dalam Adegan Perang Duryudana melawan Werkudana. Terjadi peperangan sengit antara Duryudana dengan Werkudara. Peristiwa kelima puluh lima, Werkudara berhasil memukul paha Duryudana dengan gadanya. Selain itu wajah Duryudana juga dihancurkan oleh Werkudara. Duryudana belum berhasil dihabisi. Kresna memberi pertolongan dengan meminta Werkudara melempar Duryudana ke dalam perapian besar. Duryudana meregang nyawa.

Adegan Baladewa di Kurusetra merupakan adegan berikutnya. Peristiwa kelima puluh enam termasuk dalam adegan ini. Baladewa marah karena merasa ditipu Kresna. Selain itu juga disebabkan adanya kabar bahwa Werkudara sangat kejam dan bengis dalam berperang terutama dengan Duryudana. Peristiwa kelima puluh tujuh, Baladewa mencari Werkudara lalu mengajak berperang. Peristiwa kelima puluh delapan, Kresna menemui Baladewa untuk meredam kemarahannya. Baladewa diajak untuk menyaksikan kelahiran cucu Pandawa.

Adegan Sengkuni Gugur memuat peristiwa kelima puluh sembilan, Sengkuni lari meninggalkan medan Kurusetra setelah mendengar kabar kematian Duryudana. Nakula mengejarnya dengan melepaskan panah mengenai dubur Sengkuni. Peristiwa keenam puluh, Sengkuni bersembunyi di semak-semak. Werkudara mengetahuinya lalu menangkapnya dan merobek-robek tubuh Sengkuni dari mulut hingga dubur. Sengkuni berhasil dibinasakan.

Adegan penutup adalah Adegan Negara Ngastina. Peristiwa keenam puluh satu termasuk dalam adegan ini. Kresna, Baladewa, dan Pandawa menyaksikan kelahiran Parikesit. Peristiwa keenam puluh dua, bayi Parikesit menangis tak mau diam. Setelah Puntadewa mengatakan bahwa Negara Ngastina diberikan kepadanya, tangis bayi Parikesit pun reda.

\section{Fungsi dan Urutan Fungsi dalam $L B Y$ versi Klaten}

Sebelum sampai pada pembahasan mengenai fungsi dan urutan fungsi dalam $L B Y$ versi Klaten akan ditilik kembali mengenai pengertian fungsi seperti dikemukakan oleh Propp. Pengertian fungsi yang dimaksud oleh Vladimir Propp ialah suatu tindakan (action) dari dramatis personae (peran, tokoh, pelaku), didefinisikan dari sudut pandang kepentingannya di dalam aliran tindakan. Fungsi ditetapkan dengan melihat peristiwa di dalam cerita (Propp, 1988:20-21). Mengenai urutan fungsi, Propp mengatakan bahwa pada umumnya sebuah cerita berawal dari fungsi kejahatan atau kekurangan, melalui fungsi-fungsi perantara berakhir dengan fungsi perkawinan atau fungsifungsi lain yang bertugas sebagai penyelesaian. Fungsi-fungsi yang bertugas sebagai penyelesaian kadang-kadang berupa penerimaan alat magis, penghapusan penderitaan atau kekurangan, hero (hero) diselamatkan dan sebagainya (Propp, 1988: 92).

Konsep fungsi dan urutan fungsi yang diteorikan Propp tersebut, dalam pembahasan berikut, diadaptasi untuk menentukan fungsi dan urutan fungsi dalam $L B Y$ versi Klaten. Pelacakan urutan fungsi nanti, sekaligus akan terlacak skema pergerakan cerita. $L B Y$ versi Klaten dibawakan dalam pakeliran tradisi gaya Surakarta. Oleh karena itu untuk mempermudah pelacakan fungsi, urutan fungsi, dan skema pergerakan cerita, dilakukan dengan mengikuti pakeliran tradisi gaya Surakarta seperti dikemukakan oleh Nojowirongko (1960) dan Suyanto (2007).

\section{Fungsi Pelaku dalam $L B Y$ versi Klaten}

Mengacu pada konsep Propp tentang fungsi pelaku di muka, maka pelacakan fungsi pelaku difokuskan pada penelisikan tindakan-tindakan dramatis personae atau yang disebut hero oleh Propp. Melalui pelacakan peristiwa-peristiwa dalam $L B Y$ versi Klaten rupa-rupanya ditemukan keistimewaan berkaitan dengan hero dan penjahat. Dalam $L B Y$ versi Klaten ini kiranya dapat dikemukakan bahwa yang disebut hero ialah siapa saja yang berada pada pihak Pandawa dan yang disebut penjahat ialah siapa saja yang berada pada pihak Korawa. Hal ini menyimpang dari kekhasan cerita wayang yaitu sang hero biasanya dapat dilacak dengan memperhatikan judul lakon 
tersebut, yaitu dengan mengacu pada kata lakon di antaranya berarti tokoh utama dalam cerita yang disajikan, tokoh sentral dalam suatu cerita. Pengertian ini didasarkan pada pertanyaan: lakoné sapa? 'siapakah yang menjadi tokoh sentral?' (Tim Penulis Sena Wangi, 1999: 829-830; Sutarno, 2002: 214). Oleh Karena tokoh sentral dalam $L B Y$ versi Klaten ini banyak, maka siapa saja yang berada di pihak Pandawa disebut dengan hero. Masih berkaitan dengan hero, penyimpangan ini rupa-rupanya juga disebabkan oleh penyajian cerita $L B Y$ versi Klaten yang dikemas dalam satu lakon.

Setelah sang hero dapat dilacak, maka selanjutnya ditelisik tindakan-tindakan hero atau fungsi hero dalam peristiwa-peristiwa yang menjalin cerita ini. Fungsi-fungsi pelaku dalam $L B Y$ versi Klaten yang berhasil dilacak kemudian diberi (1) ringkasan isinya; (2) definisi ringkas di dalam satu perkataan; (3) lambang konvensionalnya.

\section{Fungsi Pelaku dalam Pathet Nem}

Peristiwa yang mengawali Jejer Pesanggrahan Ngastina ialah peristiwa pertama, memuat cerita kesedihan dan kepesimisan Duryudana untuk melanjutkan perang Baratayuda. Apa yang dirasakan Duryudana itu dilatarbelakangi oleh gugurnya para senapati andalan Korawa oleh para senapati Pandawa. Peristiwa pertama ini dapat dikategorikan sebagai situasi awal.

Dengan demikian untuk fungsi yang pertama (I) ini ringkasan isinya adalah penjahat kehilangan anggota keluarganya. Definisinya ketiadaan, lambangnya $\beta$. Fungsi kedua dilacak dari peristiwa kedua yaitu peristiwa pemberian informasi oleh Sengkuni mengenai kesedihan Werkudara yang diakibatkan oleh kematian Gathutkaca, putranya. Duryuduna (penjahat) menerima informasi tentang kelemahan pihak musuhnya.

Fungsi kedua (II) ini ringkasan isinya adalah penjahat menerima informasi tentang korbannya. Definisinya penyampaian informasi, lambangnya ५. Fungsi ketiga dilacak dari peristiwa ketiga, yaitu peristiwa pengangkatan Bomawikatha dan Wikathaboma sebagai senapati agung Korawa. Kedua senapati ini diperintah untuk berperang dengan Werkudara dan dalam rangka membalas kematian para senapati Korawa.
Fungsi ketiga (III) ini ringkasan isinya adalah penjahat berniat memerangi. Definisinya kejahatan, lambangnya A. Fungsi keempat dilacak dari peristiwa keempat yaitu persiapan senapati Bomawikatha dan Wikathaboma (penjahat) untuk melakukan peperangan ke medan Kurusetra.

Fungsi keempat (IV) ini isi ringkasnya ialah penjahat sepakat untuk melakukan tindak balas. Definisinya tindak balas, lambangnya C. Fungsi kelima dilacak dari peristiwa yang terjadi dalam Adegan Kedhatonan yaitu peristiwa kelima, peristiwa Duryudana berdoa bersama demi kemenangan senapati Korawa.

Fungsi kelima (V) ini ringkasan isinya ialah penjahat memperoleh alat sakti yaitu berupa doa bersama. Definisinya pembekalan atau penerimaan alat sakti, lambangnya F. Fungsi keenam dilacak dari peristiwa dalam Adegan Pasowanan nJawi yaitu peristiwa keenam. Peristiwa keberangkatan Bomawikatha dan Wikathaboma ke medan Kurusetra. Fungsi keenam (VI) ini isi ringkasnya ialah penjahat berangkat ke medan tempur. Definisinya keberangkatan, lambangnya $\uparrow$.

Fungsi ketujuh dilacak dari peristiwa dalam Adegan Pungkuran yaitu peristiwa ketujuh, peristiwa kesedihan Werkudara akibat kematian putranya, Gathutkaca. Gathutkaca gugur di medan perang. Fungsi ketujuh (VII) ini ringkasan isinya ialah penjahat membunuh musuhnya. Definisinya kejahatan, lambangnya A.

Fungsi kedelapan dilacak dari peristiwa kedelapan yaitu peristiwa teguran dan saran Petruk kepada Werkudara. Petruk mengingatkan tentang ketidakpantasan sikap Werkudara meninggalkan medan perang. Petruk memberi saran Werkudara untuk menuntut balas kematian Gathutkaca. Selain peristiwa kedelapan fungsi kedelapan juga dilacak dari peristiwa kesembilan dan kesepuluh yaitu peristiwa sumpah Werkudara untuk membalas kematian anaknya dan kesediaan Werkudara sebagai senapati Pandawa.

Fungsi kedelapan (VIII) ini isi ringkasnya ialah hero bersepakat untuk melakukan tindak balas. Definisinya ialah tindak balas, lambangnya C.

Fungsi kesembilan dilacak dari peristiwa kesebelas, yaitu peristiwa permohonan doa restu Werkudara kepada Puntadewa dan Abiyasa yang 
disampaikan oleh Nakula dan Sadewa. Fungsi kesembilan (IX) ini ringkasan isinya ialah hero mendapat alat sakti yaitu berupa doa restu dari tetua dan leluhurnya. Definisinya pembekalan atau penerimaan alat sakti, lambangnya $\mathrm{F}$.

Fungsi kesepuluh dilacak dari peristiwa kedua belas yaitu keberangkatan Werkudara ke medan Kurusetra diiringkan Punakawan. Fungsi kesepuluh $(\mathrm{X})$ ini isi ringkasnya hero berangkat ke medan tempur. Definisinya keberangkatan, lambangnya $\uparrow$.

Fungsi kesebelas dilacak dari peristiwaperistiwa yang terdapat dalam Adegan Perang di Kurusetra yaitu peristiwa ketiga belas, perang antara Werkudara dengan Bomawikatha dan Wikathaboma. Fungsi kesebelas (XI) ringkasan isinya hero dan penjahat terlibat dalam peperangan. Definisinya perjuangan, lambangnya $\mathrm{H}$. Fungsi kedua belas dilacak dari peristiwa keempat belas, yaitu peristiwa kematian Bomawikatha dan Wikathaboma ditangan Werkudara.

Fungsi kedua belas (XII) isi ringkasnya adalah penjahat dikalahkan. Defisininya adalah kemenangan, lambangnya I.

\section{Fungsi Pelaku dalam Pathet Sanga}

Pelacakan fungsi pelaku selanjutnya didasarkan pada peristiwa-peristiwa yang terjadi dalam tataran pathet sanga. Fungsi ketiga belas dilacak dari peristiwa kelima belas yang merupakan peristiwa dalam Adegan Petamanan, yaitu peristiwa dilarangnya Dursasana meninggalkan taman.

Fungsi ketiga belas (XIII) ini ringkasan isinya ialah sebuah larangan ditujukan kepada penjahat (Dursasana). Definisinya larangan, lambangnya $\gamma$.

Fungsi keempat belas dilacak dari peristiwa keenam belas, yaitu peristiwa pelanggaran larangan yang dilakukan oleh Dursasana. Fungsi keempat belas (XIV) ringkasan isinya ialah larangan dilanggar oleh penjahat. Definisinya pelanggaran, lambangnya $\delta$.

Fungsi kelima belas dilacak dari peristiwa ketujuh belas, yaitu peristiwa keberangkatan Dursasana ke medan Kurusetra hendak menantang perang Werkudara. Fungsi kelima belas (XV) isi ringkasnya ialah penjahat berangkat ke medan tempur. Definisinya keberangkatan, lambangnya $\uparrow$.
Fungsi keenam belas dilacak dari peristiwa kedelapan belas yaitu peristiwa peperangan antara Werkudara dan Dursasana. Fungsi keenam belas (XVI) ringkasan isinya ialah hero dan penjahat terlibat dalam peperangan. Definisinya perjuangan, lambangnya $\mathrm{H}$.

Fungsi ketujuh belas dilacak dari peristiwa kesembilan belas, peristiwa pembununah Dursasana oleh Werkudara. Fungsi ketujuh belas (XVII) isi ringkasnya ialah penjahat dikalahkan. Definisinya kemenangan, lambangnya I.

Fungsi kedelapan belas dilacak dari peristiwa kedua puluh termasuk dalam Adegan Pesanggrahan Ngastina, Duryudana sedih atas kematian Dursasana oleh Werkudara. Fungsi kedelapan belas (XVIII) ini ringkasan isinya ialah hero membunuh musuhnya. Definisinya kejahatan, lambangnya A.

Fungsi kesembilan belas dilacak dari peristiwa kedua puluh satu dan peristiwa kedua puluh dua, yaitu peristiwa penawaran diri Adipati Karna sebagai senapati, dan pengangkatan Adipati Karna sebagai senapati Korawa. Fungsi kesembilan belas (XIX) ini isi ringkasnya ialah penjahat sepakat melakukan tindak balas. Definisinya tindak balas, lambangnya $\mathrm{C}$.

Fungsi kedua puluh dilacak dari peristiwa kedua puluh tiga, yaitu peristiwa keberangkatan Adipati Karna ke medan Kurusetra. Fungsi kedua puluh $(\mathrm{XX})$ ringkasan isinya penjahat berangkat ke medan tempur. Definisinya keberangkatan, lambangnya $\uparrow$.

\section{Fungsi Pelaku dalam Pathet Manyura}

Pelacakan fungsi pelaku selanjutnya didasarkan pada peristiwa-peristiwa yang terjadi dalam tataran pathet manyura. Fungsi kedua puluh satu dilacak dari peristiwa dalam Adegan Pesanggrahan Gupalawiya ialah peristiwa kedua puluh empat, yaitu peristiwa pelarangan yang ditujukan kepada hero. Kresna memberi nasihat kepada Pandawa agar supaya mereka menghindari tindakan jahat, perkataan yang tidak pantas, dan tidak melupakan ajaran-ajaran tentang budi baik dan luhur. Jika mereka melupakan nasihat itu maka kekalahan yang akan diterimanya.

Fungsi kedua puluh satu (XXI) ringkasan isinya ialah sebuah larangan ditujukan kepada hero. Definisinya larangan, lambangnya $\gamma$. 
Fungsi kedua puluh dua dilacak dari peristiwa kedua puluh lima, yaitu peristiwa pemberitahuan Setyaki tentang pengangkatan Adipati Karna sebagai senapati. Fungsi kedua puluh dua (XXII) isi ringkasnya ialah hero menerima informasi tentang korbannya. Definisinya penyampaian informasi, lambangnya $\zeta$.

Fungsi kedua puluh tiga dilacak dari peristwa kedua puluh enam, penunjukan Janaka (sebagai senapati) untuk menghadapi Adipati Karna. Janaka menerima tugas tersebut. Fungsi kedua puluh tiga (XXIII) ringkasan isinya ialah hero sepakat untuk melakukan tindak balas. Definisinya tindak balas, lambangnya C.

Fungsi kedua puluh empat dilacak dari peristiwa kedua puluh tujuh, yaitu keberangkatan Janaka ke medan Kurusetra dengan mengendarai kereta. Fungsi kedua puluh empat (XXIV) isi ringkasnya ialah hero berangkat ke medan tempur. Definisinya keberangkatan, lambangnya $\uparrow$.

Fungsi kedua puluh lima dilacak dari peristiwa dalam Adegan di Kurusetra yaitu peristiwa kedua puluh delapan, peristiwa penuntutan Hardawalika atas kematian orang tuanya oleh Janaka. Fungsi kedua puluh lima (XXV) ringkasan isinya penjahat sepakat melakukan tindak balas. Definisinya tindak balas, lambangnya $\mathrm{C}$.

Fungsi kedua puluh enam dilacak dari peristiwa kedua puluh sembilan, yaitu peristiwa diluluskannya permintaan Hardawalika oleh Adipati Karna untuk membunuh Janaka di dalam peperangan antara Adipati Karna dengan Janaka. Fungsi kedua puluh enam (XXVI) isi ringkasnya ialah penjahat mendapat bantuan. Definisinya pertolongan, lambangnya $\mathrm{D}$.

Fungsi kedua puluh tujuh dilacak dari peristiwa ketiga puluh, yaitu peristiwa peperangan antara Hardawalika dengan Janaka. Fungsi kedua puluh tujuh (XXVII) ringkasan isinya hero dan penjahat terlibat dalam peperangan. Definisinya perjuangan, lambangnya $\mathrm{H}$.

Fungsi kedua puluh delapan dilacak dari peristiwa ketiga puluh satu, yaitu peristiwa kematian Hardawalika ditangan Janaka. Fungsi kedua puluh delapan (XXVIII) ringkasan isinya adalah penjahat dikalahkan. Definisinya kemenangan, lambangnya I.

Fungsi kedua puluh sembilan dilacak dari peristiwa ketiga puluh dua yang merupakan peristiwa dalam Adegan Karna Tanding, yaitu peristiwa peperangan antara Karna dan Janaka. Fungsi kedua puluh sembilan (XXIX) isi ringkasnya ialah hero dan penjahat terlibat dalam peperangan. Definisinya perjuangan, lambangnya $\mathrm{H}$.

Fungsi ketiga puluh dilacak dari peristiwa ketiga puluh tiga, yaitu peristiwa kematian Karna oleh Janaka. Fungsi ketiga puluh (XXX) ringkasan isinya ialah penjahat dikalahkan. Definisinya kemenangan, lambangnya I.

Fungsi ketiga puluh satu dilacak dari peristiwa ketiga puluh empat yaitu peristiwa yang terdapat dalam Adegan Pesanggrahan Ngastina, yaitu peristiwa penyampaian kabar kematian Adipati Karna. Duryudana kehilangan senapatinya lagi. Fungsi ketiga puluh satu (XXXI) isi ringkasnya hero membunuh musuhnya. Definisinya kejahatan, lambangnya A.

Fungsi ketiga puluh dua dilacak dari peristiwa ketiga puluh lima dan peristiwa ketiga puluh enam, yaitu peristiwa kemarahan Salya atas laporan Aswatama tentang sebab kematian Adipati Karna. Untuk meredakan amarah Salya Durna kemudian menawarkan diri sebagai senapati Korawa. Fungsi ketiga puluh dua (XXXII) ringkasan isinya ialah penjahat sepakat melakukan tindak balas. Definisinya tindak balas, lambangnya C.

Fungsi ketiga puluh tiga dilacak dari peristiwa ketiga puluh tujuh, yaitu peristiwa keberangkatan Durna ke medan Kurusetra. Fungsi ketiga puluh tiga (XXXIII) isi ringkasnya ialah penjahat berangkat ke medan tempur. Definisinya keberangkatan, lambangnya $\uparrow$.

Fungsi ketiga puluh empat dilacak dari peristiwa yang termasuk dalam Adegan di Kurusetra berikutnya ialah peristiwa ketiga puluh delapan, yaitu peristiwa peperangan antara Durna dengan Setyaki di medan Kurusetra. Setyaki dipukul mundur. Janaka dan Werkudara hendak memberi bantuan, tetapi mereka mengurungkan niatnya karena rasa hormatnya kepada gurunya. Fungsi ketiga puluh empat (XXXIV) ringkasan isinya hero dan penjahat terlibat dalam peperangan. Definisinya perjuangan, lambangnya $\mathrm{H}$.

Fungsi ketiga puluh lima dilacak dari peristiwa ketiga puluh sembilan, yaitu peristiwa kematian Durna oleh Trusthajumena. Fungsi ketiga puluh lima (XXXV) isi ringkasnya penjahat dikalahkan. Definisinya kemenangan, lambangnya I. 
Fungsi ketiga puluh enam dilacak dari peristiwa dalam Adegan Perang Aswatama Melawan Janaka, ialah peristiwa keempat puluh satu, yaitu penuntutan Aswatama atas kematian ayahnya, Durna. Fungsi ketiga puluh enam (XXXVI) ringkasan isinya penjahat melakukan tindak balas. Definisinya tindak balas, lambangnya $\mathrm{C}$.

Fungsi ketiga puluh tujuh dilacak dari peristiwa keempat puluh dua, yaitu peristiwa peperangan antara Aswatama dengan Janaka. Fungsi ketiga puluh tujuh (XXXVII) isi ringkasnya ialah hero dan penjahat terlibat dalam peperangan. Definisinya perjuangan, lambangnya $\mathrm{H}$.

Fungsi ketiga puluh delapan dilacak dari peristiwa keempat puluh tiga, yaitu peristiwa perebutan senjataAswatama oleh Narada. Meskipun di sini Aswatama tidak dibunuh tetapi dengan dimintanya senjata Cundhamanik miliknya, dapat dikatakan dia telah mengalami kekalahan. Fungsi ketiga puluh delapan (XXXVIII) ringkasan isinya penjahat dikalahkan. Definisinya kemenangan, lambangnya I.

Fungsi ketiga puluh sembilan dilacak dari peristiwa keempat puluh empat yang termasuk dalam Adegan Pesanggrahan Ngastina, yaitu peristiwa kematian Durna. Kabar kematian Durna ini disampaikan Patih Sengkuni kepada Duryudana. Duryudana kehilangan senapatinya lagi. Fungsi ketiga puluh sembilan (XXXIX) ringkasan isinya hero membunuh musuhnya. Definisinya kejahatan, lambangnya A.

Fungsi keempat puluh dilacak dari peristiwa keempat puluh lima dan peristiwa keempat puluh enam, yaitu peristiwa penawaran diri Salya menjadi senapati Korawa dan pengangkatan Salya sebagai senapati Korawa. Fungsi keempat puluh (XL) ringkasan isinya penjahat sepakat melakukan tindak balas. Definisinya tindak balas, lambangnya $\mathrm{C}$.

Fungsi keempat puluh satu dilacak dari peristiwa keempat puluh tujuh, yaitu peristiwa keberangkatan Salya ke medan Kurusetra. Fungsi keempat puluh satu (XLI) isi ringkasnya ialah penjahat berangkat ke medan tempur. Definisinya keberangkatan, lambangnya $\uparrow$.

Fungsi keempat puluh dua dilacak dalam Adegan di Kurusetra yaitu peristiwa keempat puluh delapan dan peristiwa keempat puluh sembilan, peristiwa peperangan antara Salya melawan
Werkudara dan Janaka dan peperangan antara Salya dengan Puntadewa yang notabene adalah orang yang berdarah putih. Fungsi keempat puluh dua (XLII) ringkasan isinya ialah hero dan penjahat terlibat dalam peperangan. Definisinya perjuangan, lambangnya $\mathrm{H}$.

Fungsi keempat puluh tiga dilacak dari peristiwa kelima puluh satu, yaitu peristiwa kematian Salya oleh Puntadewa. Fungsi keempat puluh tiga (XLIII) ringkasan isinya ialah penjahat dikalahkan. Definisinya kemenangan, lambangnya I.

Fungsi keempat puluh empat dilacak dalam Adegan Pesanggrahan Ngastina yaitu peristiwa kelima puluh dua, peristiwa penyampaian kabar kematian Salya kepada Duryudana. Pihak Korawa kehilangan senapatinya lagi. Fungsi keempat puluh empat (XLIV) isi ringkasnya ialah hero membunuh musuhnya. Definisinya kejahatan, lambangnya A.

Fungsi keempat puluh lima dilacak dari peristiwa kelima puluh tiga, yaitu keberangkatan Duryudana ke medan Kurusetra sebagai senapati. Fungsi keempat puluh lima (XLV) ringkasan isinya penjahat berangkat ke medan tempur. Definisinya keberangkatan, lambangnya $\uparrow$.

Fungsi keempat puluh enam dilacak dari peristiwa kelima puluh empat termasuk peristiwa dalam Adegan Perang Duryudana Melawan Werkudara, yaitu peristiwa peperangan sengit antara Duryudana dengan Werkudara. Fungsi keempat puluh enam (XLVI) ringkasan isinya ialah hero dan penjahat terlibat dalam peperangan. Definisinya perjuangan, lambangnya $\mathrm{H}$.

Fungsi keempat puluh tujuh dilacak dari peristiwa kelima puluh lima, yaitu peristiwa kematian Duryudana Werkudara. Fungsi keempat puluh tujuh (XLVII) isi ringkasnya ialah penjahat dikalahkan. Definisinya kemenangan, lambangnya I.

Fungsi keempat puluh delapan dilacak dari peristiwa dalam Adegan Baladewa di Kurusetra merupakan peristiwa kelima puluh enam yakni peristiwa kemarahan Baladewa karena merasa ditipu Kresna. Selain itu juga disebabkan adanya kabar bahwa Werkudara sangat kejam dan bengis dalam berperang terutama dengan Duryudana. Fungsi keempat puluh delapan (XLVIII) ringkasan isinya pahlawan melakukan penipuan. Definisinya kejahatan, lambangnya A. 
Fungsi keempat puluh sembilan dilacak dari peristiwa kelima puluh tujuh, yaitu peperangan antara Baladewa dengan Werkudara. Fungsi keempat puluh sembilan (XLIX) ringkasan isinya hero dan penjahat terlibat dalam peperangan. Definisinya perjuangan lambangnya $\mathrm{H}$.

Fungsi kelima puluh dilacak dari peristiwa kelima puluh delapan, yaitu peristiwa penyelamatan Werkudara oleh Kresna dari kematian di tangan Baladewa. Kresna menemui Baladewa untuk meredam kemarahannya. Baladewa diajak untuk menyaksikan kelahiran cucu Pandawa. Fungsi kelima puluh (L) isi ringkasnya pahlawan diselamatkan. Definisinya penyelamatan, lambangnya Rs.

Fungsi kelima puluh satu dilacak dari peristiwa dalam Adegan Sengkuni Gugur yaitu peristiwa kelima puluh sembilan dan peristiwa keenam puluh, yaitu peristiwa kematian Sengkuni oleh Werkudara. Fungsi kelima puluh satu (LI) isi ringkasnya ialah penjahat dikalahkan. Definisinya kemenangan, lambangnya I.

Fungsi kelima puluh dua dilacak dari peristiwa dalam Adegan Negara Ngastina yaitu peristiwa keenam puluh satu, peristiwa kelahiran Parikesit, cucu Pandawa. Fungsi kelima puluh dua (LII) ringkasan isinya ialah kemunculan pahlawan baru. Definisinya perubahan rupa, lambangnya $T$.

Fungsi kelima puluh tiga dilacak dari peristiwa keenam puluh dua, yaitu peristiwa penobatan bayi Parikesit sebagai raja Ngastina. Fungsi kelima puluh tiga (LIII) isi ringkasnya ialah pahlawan naik tahta. Definisinya naik tahta, lambangya $\mathrm{Cr}^{2}$.

\section{Urutan Fungsi Pelaku dalam $L B Y$ versi Klaten}

Pelacakan fungsi pelaku dalam lakon $L B Y$ versi Klaten yang telah dipaparkan, menghasilkan lima puluh tiga fungsi. Namun di sini perlu dikemukakan bahwa jumlah lima puluh tiga tersebut dilacak dari tindakan banyak hero, akibatnya sering ditemukan pengulangan fungsi pelaku. Ini temuan yang pertama, yang kedua, rupa-rupanya jumlah lima puluh tiga tersebut disebabkan oleh cerita dalam $L B Y$ versi

2 Lambang ini dimodifikasi dari lambang yang diberikan olch Propp yaitu W*. Adapun alasan modifikasi lambang ini ialah hero dalam LBY versi Klaten ini tidak melalui pernikahan terlebih dahulu untuk mendapatkan tahtanya.
Klaten adalah cerita perang yang sangat panjang berlangsung selama delapan belas hari, sehingga sangat mungkin terjadi pengulangan fungsi pelaku. Jika ditelisik kembali sebenarnya fungsi pelaku yang terdapat dalam $L B Y$ versi Klaten hanya berjumlah empat belas fungsi pelaku yaitu $\beta \zeta$ A C F $\uparrow \mathrm{H} \mathrm{I} \gamma \delta \mathrm{D}$ Rs T Cr. Dikatakan oleh Propp (1988:64) bahwa sebuah cerita paling banyak mengandung tiga puluh satu fungsi pelaku. Dengan demikian $L B Y$ versi Klaten dapat dikatakan masih termasuk cerita rakyat yang tidak menyimpang dari cerita rakyat pada umumnya. Adapun urutan fungsi-fungsi dalam $L B Y$ versi Klaten adalah sebagai berikut.

1. Penjahat kehilangan anggota keluarganya. Definisinya ketiadaan, lambangnya $\beta$.

2. Penjahat menerima informasi tentang korbannya. Definisinya penyampaian informasi, lambangnya $\zeta$.

3. penjahat berniat memerangi. Definisinya kejahatan, lambangnya A.

4. penjahat sepakat untuk melakukan tindak balas. Definisinya tindak balas, lambangnya $C$.

5. penjahat memperoleh alat sakti yaitu berupa doa bersama. Definisinya pembekalan atau penerimaan alat sakti, lambangnya $F$.

6. penjahat berangkat ke medan tempur. Definisinya keberangkatan, lambangnya $\uparrow$.

7. penjahat membunuh musuhnya. Definisinya kejahatan, lambangnya A.

8. hero bersepakat untuk melakukan tindak balas. Definisinya ialah tindak balas, lambangnya $C$.

9. hero mendapat alat sati yaitu berupa doa restu dari tetua dan leluhurnya. Definisinya pembekalan atau penerimaan alat sakti, lambangnya $\mathrm{F}$.

10. hero berangkat ke medan tempur. Definisinya keberangkatan, lambangnya $\uparrow$.

11. hero dan penjahat terlibat dalam peperangan. Definisinya perjuangan, lambangnya $H$.

12. penjahat dikalahkan. Defisininya adalah kemenangan, lambangnya I.

13. sebuah larangan ditujukan kepada penjahat (Dursasana). Definisinya larangan, lambangnya $\gamma$.

14. larangan dilanggar oleh penjahat. Definisinya pelanggaran, lambangnya $\delta$.

15. penjahat berangkat ke medan tempur. Definisinya keberangkatan, lambangnya $\uparrow$. 
16. hero dan penjahat terlibat dalam peperangan. Definisinya perjuangan, lambangnya $\mathrm{H}$.

17. penjahat dikalahkan. Definisinya kemenangan, lambangnya I.

18. hero membunuh musuhnya. Definisinya kejahatan, lambangnya $\mathrm{A}$.

19. penjahat sepakat melakukan tindak balas. Definisinya permulaan tindak balas, lambangnya $\mathrm{C}$.

20. penjahat berangkat ke medan tempur. Definisinya keberangkatan, lambangnya $\uparrow$.

21. sebuah larangan ditujukan kepada hero. Definisinya larangan, lambangnya $\gamma$.

22. hero menerima informasi tentang korbannya. Definisinya penyampaian informasi, lambangnya $\zeta$.

23. hero sepakat untuk melakukan tindak balas. Definisinya tindak balas, lambangnya $\mathrm{C}$.

24. hero berangkat ke medan tempur. Definisinya keberangkatan, lambangnya $\uparrow$.

25. penjahat sepakat melakukan tindak balas. Definisinya tindak balas, lambangnya $\mathrm{C}$.

26. penjahat mendapat bantuan. Definisinya pertolongan, lambangnya $\mathrm{D}$.

27. hero dan penjahat terlibat dalam peperangan. Definisinya perjuangan, lambangnya $\mathrm{H}$.

28. penjahat dikalahkan. Definisinya kemenangan, lambangnya I.

29. hero dan penjahat terlibat dalam peperangan. Definisinya perjuangan, lambangnya $\mathrm{H}$.

30. penjahat dikalahkan. Definisinya kemenangan, lambangnya I.

31. hero membunuh musuhnya. Definisinya kejahatan, lambangnya A.

32. penjahat sepakat melakukan tindak balas. Definisinya tindak balas, lambangnya $C$.

33. penjahat berangkat ke medan tempur. Definisinya keberangkatan, lambangnya $\uparrow$.

34. hero dan penjahat terlibat dalam peperangan. Definisinya perjuangan, lambangnya $\mathrm{H}$.
35. penjahat dikalahkan. Definisinya kemenangan, lambangnya I.

36. penjahat melakukan tindak balas. Definisinya tindak balas, lambangnya $\mathrm{C}$.

37. hero dan penjahat terlibat dalam peperangan. Definisinya perjuangan, lambangnya $\mathrm{H}$.

38. penjahat dikalahkan. Definisinya kemenangan, lambangnya I.

39. hero membunuh musuhnya. Definisinya kejahatan, lambangnya A.

40. penjahat sepakat melakukan tindak balas. Definisinya tindak balas, lambangnya $\mathrm{C}$.

41. penjahat berangkat ke medan tempur. Definisinya keberangkatan, lambangnya $\uparrow$.

42. hero dan penjahat terlibat dalam peperangan. Definisinya perjuangan, lambangnya $\mathrm{H}$.

43. penjahat dikalahkan. Definisinya kemenangan, lambangnya I.

44. hero membunuh musuhnya. Definisinya kejahatan, lambangnya A.

45. penjahat berangkat ke medan tempur. Definisinya keberangkatan, lambangnya $\uparrow$.

46. hero dan penjahat terlibat dalam peperangan. Definisinya perjuangan, lambangnya $\mathrm{H}$.

47. penjahat dikalahkan. Definisinya kemenangan, lambangnya I.

48. pahlawan melakukan penipuan. Definisinya kejahatan, lambangnya A.

49. hero dan penjahat terlibat dalam peperangan. Definisinya perjuangan penjahat dikalahkan. Definisinya kemenangan, lambangnya I.

50. kemunculan pahlawan baru. Definisinya perubahan rupa, lambangnya $T$.

51. pahlawan baru naik tahta. Definisinya naik tahta, lambangya $\mathrm{Cr}$.

Urutan fungsi $L B Y$ versi Klaten seperti telah dikemukakan diatas, dapat dibuat skema urutan fungsi seperti gambar 2 berikut:

\section{I}

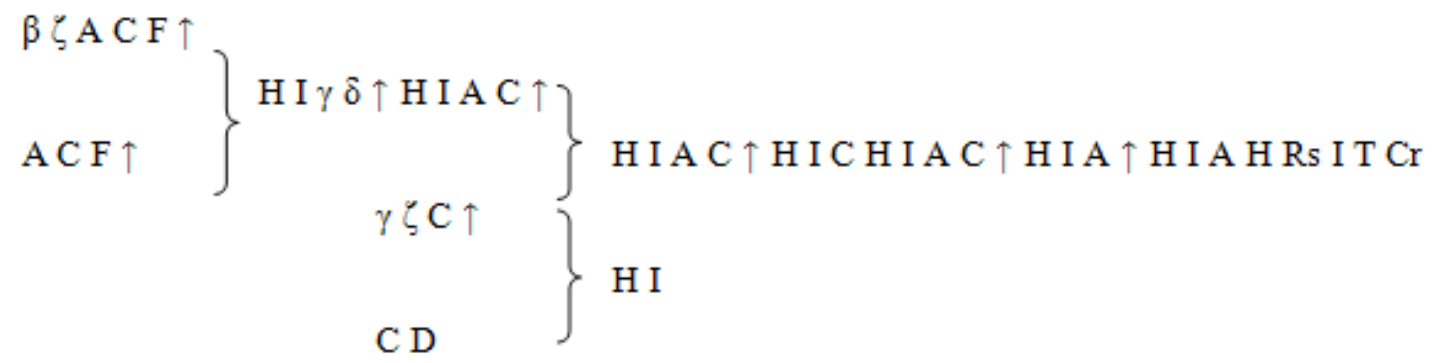

Gambar 2 skema urutan fungsi LBY versi Klaten 


\section{Skema Pergerakan Cerita Lakon Kresna Duta versi Ki Nartosabdo}

Propp (1988: 92-93) mengatakan bahwa sebuah cerita dibentuk oleh satu atau lebih pergerakan. Artinya sebuah teks kemungkinan hanya memuat sebuah cerita namun kadangkadang juga memuat lebih dari satu cerita. Memperhatikan fungsi pelaku yang berhasil dilacak di depan, rupa-rupanya dapat dikatakan bahwa $L B Y$ versi Klaten ini dibentuk oleh lebih dari satu pergerakan.

\section{Skema Pergerakan Lakon Kresna Duta versi Ki Nartosabdo dalam Pathet Nem}

Dalam $L B Y$ versi Klaten bagian pathet nem memuat enam adegan. Berdasarkan urutan fungsi yang telah dilacak maka skema pergerakan dalam pathet nem dapat dilihat pada gambar 3 .

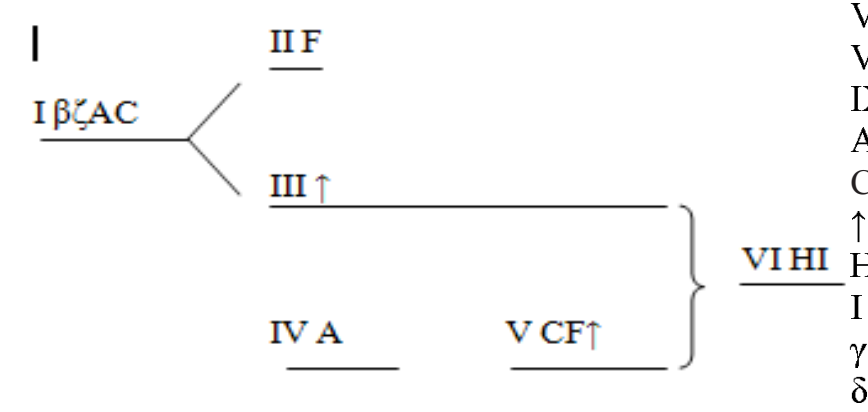

Gambar 3 Skema pergerakan cerita pada pathet nem

Keterangan:

I : Adegan Jejer Pesanggrahan Ngastina

II : Adegan Kedhatonan

III : Adegan Paseban Njawi

IV : Adegan Pungkuran

$\mathrm{V}$ : Adegan Babak Unjal

VI : Adegan di Kurusetra

A : lambang fungsi kejahatan

C : lambang fungsi permulaan tindak balas

F : lambang fungsi pembekalan

$\uparrow \quad$ : lambang fungsi keberangkatan

$\mathrm{H} \quad$ : lambang fungsi perjuangan

I $\quad$; lambang fungsi kemenangan

B : lambang fungsi ketidakhadiran

$\zeta \quad$ : lambang fungsi penyampaian informasi

$<\quad$ : pergerakan pecah

: pertemuan dua pergerakan

\section{Skema Pergerakan $L B Y$ versi Klaten dalam Pathet Sanga}

Dalam $L B Y$ versi Klaten bagian pathet sanga memuat tiga adegan. Untuk dapat mempermudah menampilkan gambar perpecahan dan pertemuan pergerakan dalam skema berikut disertakan adegan keenam dalam pathet nem. Berdasarkan urutan fungsi yang telah dilacak di depan maka skema pergerakan dalam pathet sanga seperti pada gambar 4.

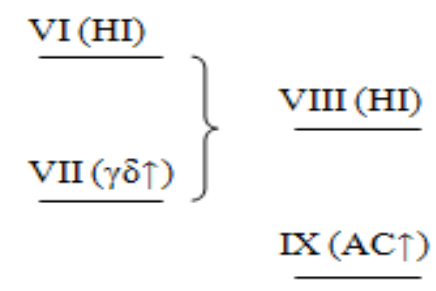

Gambar 4 Skema pergerakan cerita pada pathet sanga

Keterangan:

VII : Adegan Petamanan

VIII : Adegan di Kurusetra

IX : Adegan Pesanggrahan Ngastina

A : lambang fungsi kejahatan

C : lambang fungsi permulaan tindak balas

$\uparrow \quad$ : lambang fungsi keberangkatan

: lambang fungsi perjuangan

I ; lambang fungsi kemenangan

$\gamma \quad$ : lambang fungsi larangan

$\delta \quad$ : lambang fungsi pelanggaran

: pertemuan dua pergerakan

\section{Skema Pergerakan $L B Y$ versi Klaten dalam Pathet Manyura \\ Dalam $L B Y$ versi Klaten bagian pathet manyura memuat tiga belas adegan. Agar supaya skema berikut mudah dibaca, beberapa adegan dalam pathet sanga disertakan juga dalam gambar skema pergerakan cerita pada pathet manyura ini. Berdasarkan urutan fungsi yang telah dilacak maka skema pergerakan dalam pathet manyura dapat dilihat pada gambar 5 .}




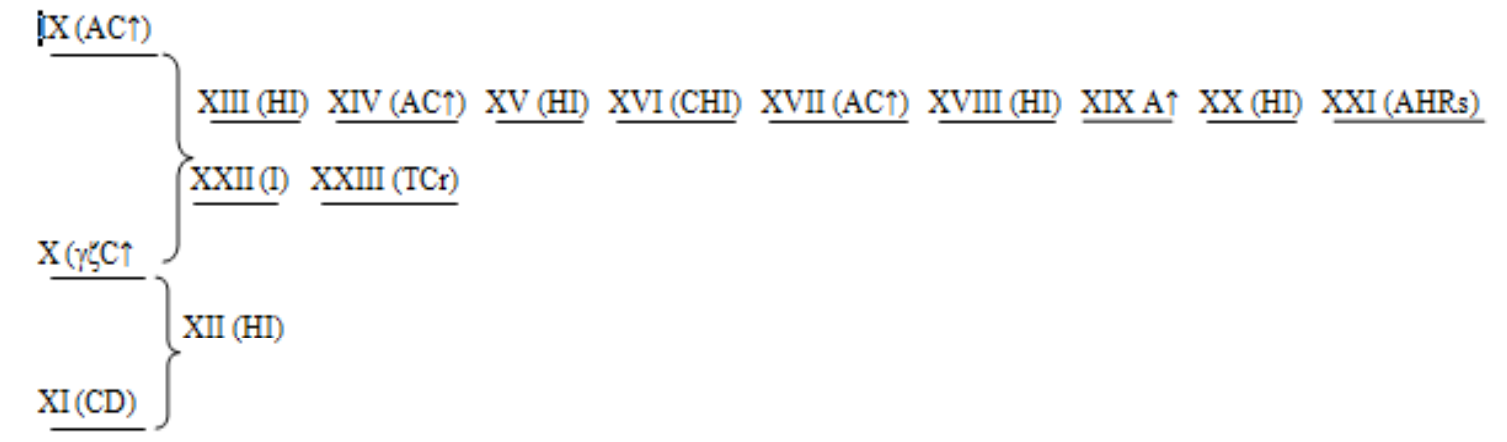

Gambar 5 Skema pergerakan cerita pada pathet manyura

Keterangan:

IX : Adegan Pesanggrahan Ngastina

$\mathrm{X}$ : Adegan Pesanggrahan Gupalawiya

XI : Adegan di Kurusetra

XII : Adegan di Kurusetra

XIII : Adegan Karna Tanding

XIV : Adegan Pesanggrahan Ngastina

XV : Adegan di Kurusetra

XVI : Adegan Perang Aswatama melawan Janaka

XVII : Adegan Pesanggrahan Ngastina

XVIII : Adegan di Kurusetra

XIX : Adegan Pesanggrahan Ngastina

XX : Adegan Perang Duryudana dengan Werkudara

XXI : Adegan Baladewa di Kurusetra

XXII : Adegan Sengkuni Gugur

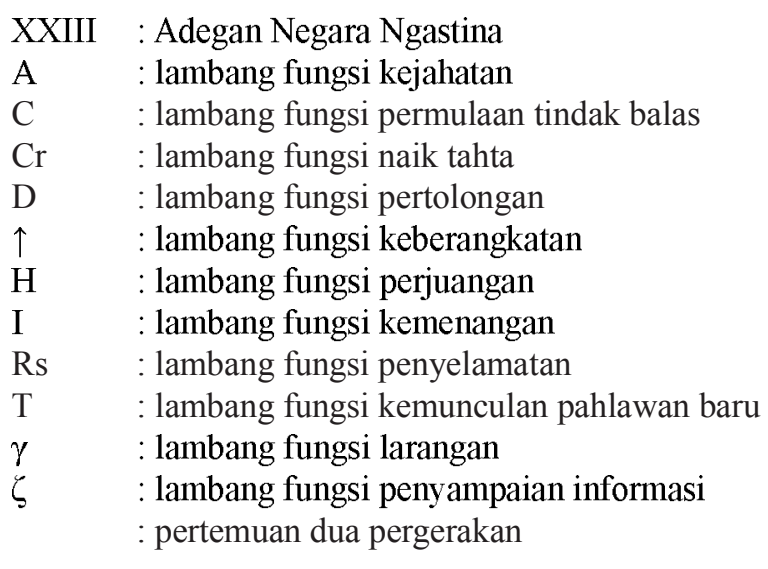

Setelah skema pergerakan cerita dari pathet demi pathet dikemukakan, diperoleh skema pergerakan $L B Y$ versi Klaten seperti gambar 6 .

\section{Penutup}

Ada beberapa hal yang dapat dikemukakan dari kajian struktur naratif $L B Y$ versi Klaten. Pertama, ditemukan lima puluh tiga fungsi yang dilacak dari aliran tindakan banyak hero dalam $L B Y$ versi Klaten. Namun jika dicermati $L B Y$ versi Klaten hanya mengandung empat belas fungsi pelaku. Hal ini terjadi karena ada fungsi pelaku yang berulang beberapa kali yang disebabkan $L B Y$ versi Klaten merupakan lakon perang yang sangat panjang.

Kedua, Lakon Kresna Duta versi Ki Nartosabdo sebagai cerita rakyat Jawa yang dipentaskan, ia memiliki kekhasan yaitu mengandung lebih dari satu pergerakan cerita utama. Ketiga, berkaitan dengan teori Propp yang didasarkan pada penelitiannya terhadap seratus cerita rakyat Rusia, diperoleh satu pandangan bahwa teori Propp tentang struktur naratif cerita rakyat juga berlaku

untuk cerita rakyat Jawa, meskipun ada deviasi dalam hal urutan fungsi.

Penelitian ini merupakan studi kasus $L B Y$ versi Klaten. Lakon-lakon Baratayuda versi lain belum dikaji sehingga penelitian ini belum sampai pada penemuan pola struktur naratif Lakon Baratayuda. Penelitian Lakon Baratayuda yang lain akan melengkapi penelitian ini sehingga pola struktur naratif Lakon Baratayuda dapat ditemukan.

\section{Kepustakaan}

Heroesoekarto. 1961. Ungkapan dan Hukum Karma dalam Bharata Yuda. Surabaya: GRIP.

Kats., J. 1929. Het Javaansche Toneel: Wayang Porwa I. Weltevreden: Comissie Voor de Volk Lectuur.

Krystiadi, 2010. “Teks Lakon Baratayuda versi Klaten”. Manuskrip.

Marsono. 1993. "Makna Lakon Baku pada Upacara Tradisional Tahunan di Lingkungan Masyarakat Jawa Tengah" dalam Jurnal Seni Vol. 3 No. 1. 
Nojowirongko, M. Ng. 1960. Serat Tuntunan Pedalangan Jilid I. Jogjakarta: Djawatan Kebudayaan Kementrian P.P. dan K

Propp, Vladimir. 1988. Morphology of the Folktale. London: University of Texas Press.

Radyomardowo, dkk. 1959. Serat Baratayuda. Yogyakarta: Kedaulatan Rakyat.

Subalidinata, R.S. 1989. Menguak Pustaka dan Cerita Pewayangan. Yogyakarta: Paper Seminar Sastra Pewayangan.

Sudjiman, Panuti. 1990. Kamus Istilah Sastra. cet. III. Jakarta: UI - Press.
Sutarno. 2003. Pakeliran Pujosumarto, Nartosabdo dan Pakeliran Dekade 1996-2001. Surakarta: STSI Press.

Suyanto. 2007. Teori Pedalangan: Bunga Rampai Elemen-elemen Dasar Pakeliran. Surakarta: STSI Press.

Tim Penulis Sena Wangi. 1999. Ensiklopedi Wayang Indonesia, Jilid III. Jakarta: Penerbit Sena Wangi.

\section{Audio-visual}

Kristiaji. 2005. Baratayuda. Kaset rekaman audiovisual (koleksi pribadi). 